\title{
NOVEL ARYL/ALKYL AZOLE DERIVATIVES AS AN ANTI-NOCICEPTIVE AND ANTI-INFLAMMATORY DRUG CANDIDATES
}

\author{
YESIM KAYA-YASAR ${ }^{1,3 *}$, ELIF NUR BARUT ${ }^{1}$, SECKIN ENGIN $^{1}$, \\ INCI SELIN DOGAN ${ }^{2,3}$ and SENA F. SEZEN ${ }^{1,3}$ \\ ${ }^{1}$ Department of Pharmacology, Faculty of Pharmacy, \\ ${ }^{2}$ Department of Pharmaceutical Chemistry, Faculty of Pharmacy, \\ ${ }^{3}$ Drug and Pharmaceutical Technology Application and Research Center, \\ Karadeniz Technical University, Trabzon, Turkey
}

\begin{abstract}
Novel aryl/alkyl azole derivative compounds $\mathbf{C} \mathbf{1}$ and $\mathbf{C} \mathbf{2}$ were screened for in vivo anti-nociceptive and anti-inflammatory activities by using the hot plate test and formalin-induced hind paw edema test, respectively. The ability of these compounds to inhibit cyclooxygenase- $1 / 2$ (COX-1/2) and 5/15-lipoxygenase (5/15LOX) were evaluated in vitro by using a colorimetric method. C1 (30 and $50 \mathrm{mg} / \mathrm{kg}$, i.p.) and $\mathbf{C 2}(3$ and 30 $\mathrm{mg} / \mathrm{kg}$, i.p.) increased the latency to withdrawal in the hot plate test, indicating an anti-nociceptive activity. $\mathbf{C 1}(30$ and $50 \mathrm{mg} / \mathrm{kg}$ ) and $\mathbf{C 2}(3,30$ and $50 \mathrm{mg})$ were able to decrease formalin-induced edema, indicating their anti-inflammatory properties. $\mathbf{C} \mathbf{1}$ and $\mathbf{C 2}$ exhibited inhibitory effects on the activity of COX(1-2) and 15-LOX. However, neither $\mathbf{C} 1$ nor $\mathbf{C} 2$ showed an inhibitory effect on 5-LOX. This study demonstrates that $\mathbf{C} \mathbf{1}$ and $\mathbf{C 2}$ have anti-nociceptive and anti-inflammatory activities, that are partially mediated by inhibition of COX and LOX enzymes. Our results suggest that $\mathbf{C} \mathbf{1}$ and $\mathbf{C 2}$, novel aryl/alkyl azole compounds, could serve as lead compounds to develop novel therapeutic options for the treatment of pain and inflammation.
\end{abstract}

Keywords: pain, inflammation, aryl/alkyl azole, COX-LOX, formalin-induced hind paw edema test, hot plate test

Pain is defined as 'an unpleasant sensory and emotional experience associated with actual or potential tissue damage or described in terms of such damage' by the International Association for the Study of Pain (IASP) (1). Various dimensions of pain are used for classification, such as duration (acute versus chronic) or pathophysiology (neuropathic versus nociceptive). Acute pain commonly results from tissue damage or inflammation related to trauma, infection and hypoxia and serves a protective mechanism against harmful stimuli. On the other hand, it is estimated that over 1.5 billion people are suffered from chronic pain that is a significant health problem with a high medical, social and financial impact $(2,3)$. Non-steroidal anti-inflammatory drugs (NSAIDs), opioid derivatives like morphine, are currently available drugs to treat pain. NSAIDs exhibit antinociceptive and antiinflammatory effects by suppressing the synthesis of prostanoids involved in pain and inflammatory response due to cyclooxygenase (COX) inhibition.
NSAIDs are less effective in some kind of painful conditions like neuropathic pain. Moreover, longterm use of NSAIDs is associated with serious side-effects such as gastric ulcers, nephropathy and congestive heart failure, which limit their clinical utility (4-6). Opioids derivatives are the most effective drugs for pain treatment. However, their use is limited by drug-induced tolerance, dependence and side effects such as respiratory depression and constipation (2). Recently, anticonvulsant or antidepressant drugs such as carbamazepine, gabapentin, pregabalin, amitriptyline, desipramine, duloxetine, venlafaxine have been used in the treatment of neuropathic type pain. But, their clinical use is limited due to their poor efficacy and several side-effects (3). Therefore, there is an ongoing need to develop novel anti-nociceptive and antiinflammatory drugs with an improved efficacy and safety profile.

Aryl/alkyl azoles are a novel generation of anticonvulsant drugs including nafimidone and den-

\footnotetext{
* Corresponding author: e-mail: yesimyasarkaya@ktu.edu.tr
} 
zimol. They decrease neuronal hyperexcitability by inhibiting voltage-dependent sodium channels (VDSC) like carbamazepine and phenytoin $(7,8)$. VDSCs are crucial for neuronal excitability and signaling in central and peripheral nervous systems. Expressions of several ion channels like sodium and calcium channels have been shown to be augmented in chronic inflammatory pain. A large body of evidence suggests VDSC as therapeutic targets for antinociceptive drugs (9). Suter et al. showed that rufinamide, a VDSC blocker, attenuated mechanical allodynia in a mouse model of diabetic neuropathy (10). Kamisli et al. also reported that nafimidone oxime ester derivatives are effective in reducing thermal hypoalgesia in diabetic mice (11).

Arachidonic acid (AA), a polyunsaturated fatty acid-containing 20-carbon, is released from membrane phospholipids by phospholipase A2 and it undergoes metabolism mediated by COX and lipoxygenases (LOX) $(12,13)$. AA is metabolized to PGs like PGD2, PGE2, PGF2 $\alpha$, and PGI2 by $\mathrm{COX}$ that is implicated in physiologic functions and pathological conditions. COX exists in two isoforms: a constitutive (COX-1) and an inducible form (COX-2). COX-1 catalyzes the formation of prostanoids which mediates gastrointestinal, renal and homeostatic functions, wheres $\mathrm{COX}-2$ is involved in inflammation and cancer (14). COX-1 and COX-2 are inhibited by NSAIDs that are widely prescribed to treat inflammation and pain. However, NSAIDs are associated with gastrointestinal and renal effects due to COX-1 inhibition. Therefore, selective COX-2 inhibitors like the coxibs have gained attention in the treatment of inflammatory diseases. However, their clinical use was diminished due to severe cardiovascular toxicity (15). Thus there has been a growing interest in identifying new strategies to develop novel NSAIDs with improved efficacy and safety (16). Many studies have focused to develop effective compounds combining COX inhibitory effect with other mechanisms involved in inflammation and pain (17).
1-Phenyl-2-(1H-imidazol-1-yl) ethyl 2-propyl pentanoate hydrochloride (C1) and 1-(4-Chlorophenyl)-2-(1H-imidazol-1-yl) ethyl cyclohexane carboxylate hydrochloride (C2) synthesized by Dogan et al. are novel aryl/alkyl azole substituents derived from nafimidone and denzimol (Fig. 1A and 1B). It was reported that $\mathbf{C} 1$ and $\mathbf{C 2}$ have anticonvulsant and antimicrobial activity (18). The objective of the present study is to investigate the antinociceptive, anti-inflammatory effects of $\mathbf{C 1}$ and $\mathbf{C 2}$ on experimentally-induced pain and acute inflammation and to determine the inhibitory effect of these compounds on COX1-2 and 5-,15-LOX in vitro.

\section{EXPERIMENTAL}

\section{Animals}

Male Balb/c mice weighing 25-30 g were housed in plastic cages in a temperature-humidity controlled environment $\left(22 \pm 2^{\circ} \mathrm{C}\right.$ and $60 \pm 5 \%$, respectively) with 12-hours light-dark cycle. Animals were allowed free access to food and water. The protocol was approved by the Karadeniz Technical University Animal Research Ethics Committee (Approval number: 2016/47). All animal procedures were conducted in accordance with the Guide for the Care and Use of Laboratory Animals.

\section{Chemicals}

C1 and C2 were synthesized by Dogan et al. based on the previously described methods (18). The following chemicals were used in the assays: diclofenac sodium (Sigma, USA) and morphine hydrochloride (Osel Pharma, Turkey). In addition, COX and LOX commercial assay kits (Cayman Chemical, USA) were used for in vitro enzyme inhibition studies. C1 and C2 were dissolved in the vehicle containing 1\% dimethyl sulfoxide (DMSO) in saline and administrated intraperitoneally (i.p). Morphine hydrochloride was diluted in saline and administrated subcutaneously (s.c). Diclofenac sodium was dissolved in saline and administrated i.p.
A<smiles>CCCCC(=O)OC(Cn1cnc(Cl)c1)c1ccccc1</smiles>

B<smiles>CC(OC(=O)C1CCCCC1)c1ccc(Cl)cc1</smiles>

Figure 1. Chemical structures of C1 (A) and C2 (B). 


\section{Anti-nociceptive activity}

The anti-nociceptive activity of $\mathbf{C 1}$ and $\mathbf{C 2}$ was evaluated by the hot-plate test (COMMAT Ltd, Ankara, Turkey) with some modifications of the method described previously (19). Mice were randomly divided into the following 8 groups: control (vehicle), C1 (3; 30; $50 \mathrm{mg} / \mathrm{kg}), \mathbf{C 2}(3 ; 30 ; 50$ $\mathrm{mg} / \mathrm{kg})$; morphine $(10 \mathrm{mg} / \mathrm{kg}$, positive control). Mice were placed on a metal surface maintained at $55 \pm 0.1^{\circ} \mathrm{C}$. The time until the animals exhibit reactions such as licking hind paws or jumping was recorded as latency. Latency was used as an index of nociception and increase in latency was defined as anti-nociception. Latency values were presented as seconds (s). Latencies were measured before and at $15,30,45$ and $60 \mathrm{~min}$ after the drug administration. Cut off time was set as $30 \mathrm{~s}$ to avoid tissue damage in mice.

\section{Anti-inflammatory activity}

The anti-inflammatory activity of $\mathbf{C 1}$ and $\mathbf{C 2}$ was evaluated by formalin-induced hind paw edema test with some modifications of the method described previously (20). Mice were randomly divided into the following 8 groups: control (vehicle), C1 (3; 30; $50 \mathrm{mg} / \mathrm{kg}), \mathbf{C 2}(3 ; 30 ; 50 \mathrm{mg} / \mathrm{kg})$; diclofenac $(10 \mathrm{mg} / \mathrm{kg}$, positive control). Intraplantar injection of $1 \%$ formalin $(20 \mu \mathrm{L})$ was applied to the plantar surface of the right paws of the mice $30 \mathrm{~min}$ after drug administration to induce edema. Before and $30 \mathrm{~min}$ after the formalin injection, paw thickness and volume were measured with compass and plethysmometer, respectively. The amount of increase in edema thickness and volume was calculated subtracting the respective measurements before and $30 \mathrm{~min}$ after the formalin injection. Paw thickness was presented as millimeter $(\mathrm{mm})$, whereas paw volume was presented as microliter $(\mu \mathrm{L})$.

\section{COX inhibitory activity}

The ability of $\mathbf{C 1}$ and $\mathbf{C 2}$ to inhibit COX-1 (ovine) and COX-2 (human recombinant) was determined by using enzyme immunoassay (EIA) kit (Cayman Chemical Company, Item Number 701050), following the manufacturer instructions. C1 $\left(10^{-8}-10^{-4} \mathrm{M}\right), \mathbf{C} 2\left(10^{-8}-10^{-4} \mathrm{M}\right)$; diclofenac $\left(10^{-8}\right.$ $\left.10^{-4} \mathrm{M}\right)$ and DMSO were used as positive and negative controls, respectively. The absorbance at 590 $\mathrm{nm}$ was read by using a microplate reader.

\section{LOX inhibitory activity}

The ability of $\mathrm{C} 1$ and $\mathrm{C} 2$ to inhibit 15-LO (soybean) and 5-LO (potato) using the LOX inhibitor screening assay kit (Cayman Chemical Company,
Item Number 760700), following the manufacturer instructions. C1 $\left(10^{-8}-10^{-4} \mathrm{M}\right), \mathbf{C 2}\left(10^{-8}-10^{-4} \mathrm{M}\right)$; nordihydroguaiaretic acid (NDGA) and DMSO were used as positive and negative controls, respectively. The absorbance at $490 \mathrm{~nm}$ was read by using a microplate reader.

\section{Statistical analysis}

All values were expressed as mean \pm SEM. Maximal possible effect (MPE) values were calculated and represented as [(latency-baseline)/(cut off time (30 min)-baseline)]X100. Inhibitory effects of $\mathrm{C} 1$ and $\mathrm{C} 2$ on COX and LOX were presented as a maximal effect $\left(\mathrm{E}_{\max }\right)$. $\mathrm{IC}_{50}$ was calculated as the negative logarithm of the concentration that causes $50 \%$ of the maximal inhibition.

The data were analyzed statistically by ANOVA followed by Bonferroni's test as post-hoc. Statistical analysis was carried out using GraphPad Prism version 5.01 (GraphPad Software Inc.). P < 0.05 is considered significant.

\section{RESULTS}

\section{Anti-nociceptive activity}

Administration of $\mathbf{C 1}$ or $\mathbf{C 2}$ dose-dependently increased the latency values in the hot plate test. As for C1, at $30 \mathrm{mg} / \mathrm{kg}$ (30; $60 \mathrm{~min})$ and $50 \mathrm{mg} / \mathrm{kg}$ (15$60 \mathrm{~min}$ ) doses, but not at $3 \mathrm{mg} / \mathrm{kg}$ dose increased the latency when compared to that of control; MPE values were calculated as, $18.41 \pm 4.66$ at $15 \mathrm{~min}$; $28.79 \pm 9.00$ at $30 \mathrm{~min} ; 21.19 \pm 8.23$ at $45 \mathrm{~min}$; $24.75 \pm 10.88$ at $60 \mathrm{~min}$ for $30 \mathrm{mg} / \mathrm{kg}, 26.68 \pm 4.75$ at $15 \mathrm{~min} ; 26.22 \pm 13.73$ at $30 \mathrm{~min} ; 24.17 \pm 6.37$ at 45.min; $24.04 \pm 12.43$ at $60 \mathrm{~min}$ for $50 \mathrm{mg} / \mathrm{kg}$. At the same time, the latency values were found similar to the morphine group at $30 \mathrm{mg} / \mathrm{kg}$ (30 $\mathrm{min})$ and 50 $\mathrm{mg} / \mathrm{kg}$ (15-45 $\mathrm{min}$ ) doses in the $\mathbf{C 1}$ treatment group. As for C2, increased latency values at $3 \mathrm{mg} / \mathrm{kg}$ (45 $\mathrm{min})$ and $30 \mathrm{mg} / \mathrm{kg}$ (60 $\mathrm{min})$ doses; MPE values were calculated as $17.65 \pm 6.29$ at $15 \mathrm{~min} ; 21.03 \pm$ 7.56 at $30 \mathrm{~min} ; 34.20 \pm 10.90$ at $45 \mathrm{~min} ; 12.58 \pm$ 4.90 at $60 \mathrm{~min}$ for $3 \mathrm{mg} / \mathrm{kg} ; 24.66 \pm 3.78$ at $15 \mathrm{~min}$; $34.27 \pm 8.51$ at $30 . \mathrm{min} ; 32.24 \pm 4.19$ at $45 \mathrm{~min}$; $33.07 \pm 7,22$ at $60 \mathrm{~min}$ for $30 \mathrm{mg} / \mathrm{kg}$. However C2 did not alter latencies at $50 \mathrm{mg} / \mathrm{kg}$ dose. Furthermore, the latency values of $\mathbf{C 2}(3 \mathrm{mg} / \mathrm{kg})$ and morphine group were similar to each other.

Morphine $(10 \mathrm{mg} / \mathrm{kg})$ which was used as a positive control increased latency values on 15-45. min. compared with the control group. MPE values were elicited as $44.48 \pm 6.37$ at $15 \mathrm{~min} ; 37.60 \pm 5.61$ at 30 $\min ; 29.35 \pm 4.47$ at $45 \mathrm{~min} ; 19.25 \pm 5.15$ at $60 \mathrm{~min}$ for morphine group (Fig. 2). 


\section{Anti-inflammatory activity}

We performed the formalin-induced hind paw edema test to evaluate the anti-inflammatory activity of $\mathbf{C 1}$ and $\mathbf{C 2}$. Intraplantar injection of $1 \%$ formalin caused a marked increase both in edema thickness and volume. $\mathbf{C 1}$ at $3 \mathrm{mg} / \mathrm{kg}$ was not able to decrease edema thickness and volume. However, 30 and $50 \mathrm{mg} / \mathrm{kg}$ doses of $\mathbf{C 1}$ significantly decreased edema thickness and volume compared with the control group, demonstrating that $\mathbf{C 1}$ has a dosedependent anti-inflammatory effect. C2 at three doses tested significantly reduced edema thickness compared with the control group, suggesting a higher potency of $\mathbf{C 2}$ compared to $\mathbf{C 1}$. (Fig. 3a and 3b).

\section{COX inhibitory activity}

To investigate a possible mechanism of action of anti-inflammatory activity, we examined the concentration-dependent inhibitory effect of C1 and C2 (10$\left.{ }^{8}-10^{-3} \mathrm{M}\right)$ on the COX-1 and COX-2 in vitro. C1 inhibited $\mathrm{COX}-1$ at the $10^{-7}-10^{-4} \mathrm{M}$ concentrations $\left(\mathrm{E}_{\max }=\right.$ $68.69 \pm 0.76 \%$ ); the inhibitory effect of $\mathbf{C 1}$ was not in a concentration-dependent manner, we calculated $\mathrm{IC}_{50}$ value of $\mathbf{C 1}$ for COX-1 as 4.56. In addition, $\mathbf{C 2}$ inhibited COX -1 only at the $10^{-5} \mathrm{M}\left(\mathrm{E}_{\max }=16.51 \pm 0.21 \%\right)$, $\mathrm{IC}_{50}$ value of $\mathrm{C} 2$ could not calculated for COX-1. Diclofenac $\left(10^{-8}-10^{-3} \mathrm{M}\right)$ displayed a concentrationdependent inhibitory effect on COX-1; $\mathrm{E}_{\max }$ and $\mathrm{IC}_{50}$ values were $101.14 \pm 0.26$ and 7.26 , respectively.

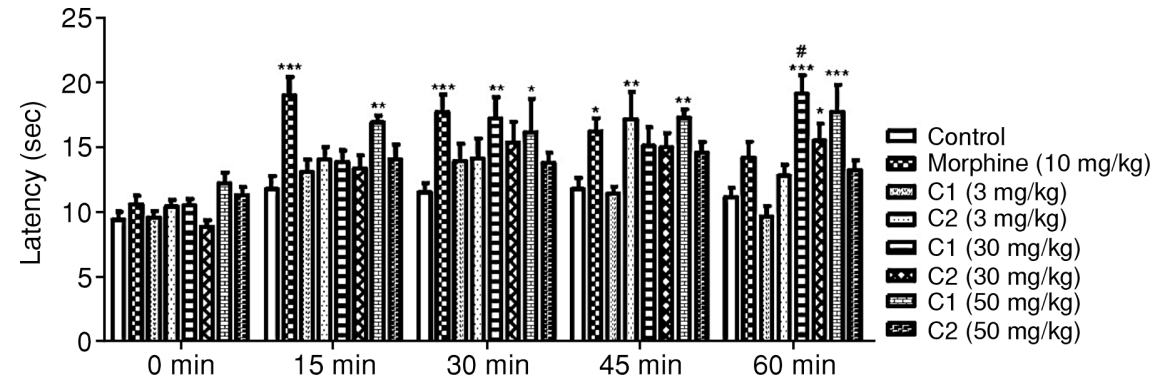

Figure 2. Effect of C1, C2 and morphine on the latency in hot plate test. Data are expressed as mean \pm SEM $(\mathrm{n}=7-12) . * \mathrm{p}<0.05, * * \mathrm{p}<$ $0.01, * * * \mathrm{p}<0.001$ compared with control, $\# \mathrm{p}<0.01$ compared with morphine.

A

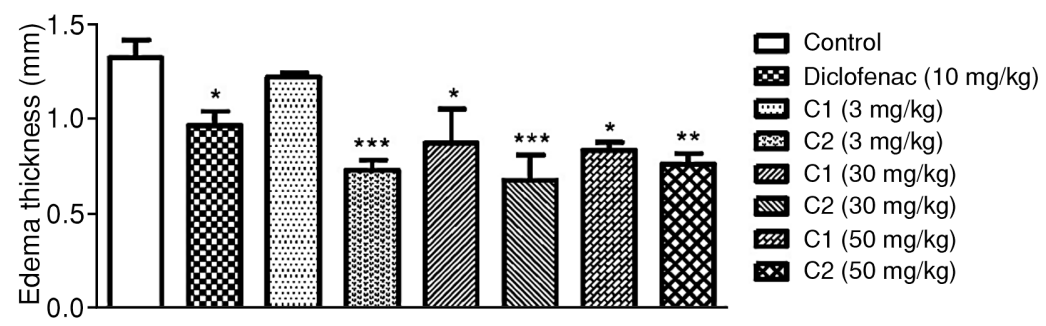

B

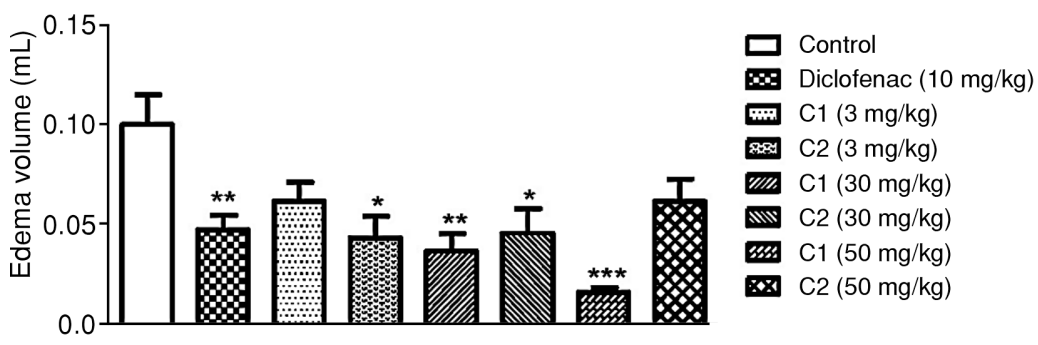

Figure 3. Effect of C1, C2 and diclofenac on edema thickness (A) and edema volume (B) in formalin-induced hind paw edema test. Data are expressed as mean \pm SEM $(\mathrm{n}=5-12)$. ${ }^{*} \mathrm{p}<0.05, * * \mathrm{p}<0.01, * * * \mathrm{p}<0.001$ compared with control. 
Table 1. In vitro COX-1 and COX-2 enzyme inhibition data.

\begin{tabular}{|c|c|c|c|c|c|}
\hline COX-1 & $0.1 \mu \mathrm{M}$ & $1 \mu \mathrm{M}$ & $10 \mu \mathrm{M}$ & $100 \mu \mathrm{M}$ & $\mathrm{IC}_{50}(\mu \mathrm{M})$ \\
\hline $\mathrm{C} 1$ & $66.12 \pm 0.38$ & $68.69 \pm 0.76$ & $55.70 \pm 0.62$ & $32.76 \pm 0.52$ & 4.56 \\
\hline $\mathrm{C} 2$ & - & - & $16.51 \pm 0.21$ & - & - \\
\hline Diclofenac & $64.18 \pm 0,46$ & $88.32 \pm 0.83$ & $101.14 \pm 0.26$ & $96.46 \pm 0.97$ & 7.26 \\
\hline COX-2 & $60.09 \pm 0.23$ & $13.78 \pm 0.33$ & $16.72 \pm 0.90$ & $17.16 \pm 0.34$ & 5.88 \\
\hline C1 & $31.33 \pm 1.39$ & $42.18 \pm 0.43$ & $44.21 \pm 0.42$ & - & 7.25 \\
\hline C2 & $60.01 \pm 0.22$ & $91.91 \pm 0.51$ & $92.24 \pm 0.93$ & $94.42 \pm 0.81$ & 6.99 \\
\hline
\end{tabular}

C1 inhibited COX-2 at $10^{-7}-10^{-4} \mathrm{M}$ concentrations. $\mathrm{E}_{\max }$ and $\mathrm{IC}_{50}$ values were calculated as 60.09 \pm 0.23 and 5.88 , respectively. The inhibitory effect of $\mathbf{C 1}$ on COX-2 was not concentration-dependent. Furthermore, C2 showed a concentration-independent inhibitory effect on COX-2; $\mathrm{E}_{\max }$ and $\mathrm{IC}_{50}$ values were $44.21 \pm 0.42$ and 7.25 , respectively. Diclofenac $\left(10^{-8}-10^{-3} \mathrm{M}\right)$ inhibited COX-2 enzyme; the inhibition was concentration-dependent. $\mathrm{E}_{\max }$ and $\mathrm{IC}_{50}$ values were calculated as $94.42 \pm 0.81$ and 6.99 , respectively (Table 1 ).

\section{LOX inhibitory activity}

The concentration-dependent inhibitory effect of $\mathbf{C 1}$ and $\mathbf{C 2}\left(10^{-8}-10^{-3} \mathrm{M}\right)$ were investigated on the 15- and 5-LOX in vitro. C1 and C2 inhibited 15-LO enzyme at only $10^{-4} \mathrm{M}, \mathrm{E}_{\max }$ values were calculated for $\mathbf{C 1}$ and $\mathbf{C 2}$ as $18.80 \pm 2.67$ and $3.97 \pm 0.05$, respectively. NDGA which was used as positive control inhibited 15-LO $\left(\mathrm{E}_{\max }=89.06 \pm 9.18\right)$. Neither $\mathbf{C 1}$ nor $\mathbf{C 2}$ showed an inhibitory effect on 5LO.

\section{DISCUSSION AND CONCLUSION}

In this study, we have demonstrated that $\mathbf{C 1}$ and C2, aryl-alkyl azole derivatives, have anti-nociceptive effect in hot plate test and presented an antiinflammatory effect on acute edema formalininduced hind paw edema test. Moreover, these effects of $\mathbf{C 1}$ and $\mathbf{C 2}$ were partially related to COX and LOX inhibition. We used a hot plate test to investigate the anti-nociceptive effects of $\mathbf{C 1}$ and C2. According to our results, C1 (30 and $50 \mathrm{mg} / \mathrm{kg}$ ) and $\mathbf{C 2}$ ( 3 and $30 \mathrm{mg} / \mathrm{kg}$ ) increased the latency in the hot plate test, indicating anti-nociceptive activity. Moreover, the onset of the anti-nociceptive activity of C2 was faster than C1. The time delay of the onset of the $\mathbf{C 1}$ effect may be due to the active metabolites of $\mathbf{C 1}$.
We used the formalin-induced hind paw edema test to evaluate the anti-nociceptive activity of $\mathbf{C 1}$ and C2. In this test, $\mathbf{C 1}$ and $\mathbf{C 2}$ decreased edema thickness and volume, indicating their anti-inflammatory properties. C2 exerted anti-inflammatory effect at $3 \mathrm{mg} / \mathrm{kg}$ which is lower than the effective dose of C1, suggesting higher potency of C2. Furthermore, we performed in vitro enzyme inhibition studies to investigate whether COX and LOX inhibition underly the mechanism of anti-nociceptive and anti-inflammatory activities of $\mathbf{C 1}$ and $\mathbf{C 2}$. Both compounds inhibited COX-1 and COX-2, in a concentration-independent manner. Although the inhibitory potency of $\mathbf{C 1}$ on $\mathrm{COX}-1$ and $\mathrm{COX}-2$ enzymes was higher than that of $\mathbf{C 2}$; the selectivity of $\mathbf{C 2}$ against COX-2 was greater than C1. In addition, $\mathbf{C 1}$ and $\mathbf{C 2}$ slightly inhibited 15-LOX; the enzyme inhibitory potency of $\mathbf{C 1}$ was higher than C2. These results suggest that inhibition of COX-1, COX-2 and partially 15 -LOX involved in the antiinflammatory activity of C1. Also, the anti-inflammatory activity of $\mathbf{C 2}$ may be related to its inhibitory effects on COX-1 and COX-2 enzyme inhibition. It has been suggested that several compounds containing azole substituents are anti-inflammatory by inhibiting COX. These novel compounds appear to be promising in the discovery of new analgesic drugs (21). Lamie et. al. demonstrated that the 4chloro benzoxazole derivative, one of the compounds derived from 1,2-diaryl-4-substituted-benziliden-5(4H)-imidazolon, is an inhibitor of COX-2 and 5-LOX activity. It has been also reported that this compound has greater selectivity against COX2 when compared to COX-1 (22). Other studies reported that substituted 1,3,4-oxadiazole/tiadiazole and 1,2,4 triazole compounds have anti-inflammatory activities (23-26). Similarly, Sowmya et. al. showed that methoxy-asetamido pyrrolyl oxazole exerted anti-inflammatory activity in a rat model of carrageenin-induced edema test (27). Synthesis of 
novel compounds that contain thiazolyl-carbonyltiyosemikarbazid thiazolyl-azole moiety has been reported to exhibit antioxidant and anti-inflammatory activities by inhibiting inducible nitric oxide synthase in an experimental model of inflammation (28).

Our present study demonstrated that novel aryl-alkyl azole derivatives $\mathbf{C 1}$ and $\mathbf{C 2}$ have antinociceptive and anti-inflammatory activities in mice, which is partially due to their COX and LOX inhibitory properties. To our knowledge, this is the first in vivo and in vitro study demonstrating that these compounds could serve as potential lead compounds in the development of novel anti-nociceptive and anti-inflammatory drugs. Future studies will be important to further clarify these effects in other models of pain and inflammation to understand underlying mechanisms of actions.

\section{Acknowledgment}

This study was supported by the Karadeniz Technical University Scientific Research Projects Coordination Unit (Project Number: THD-20187315).

\section{Conflict of interest}

There is no conflict of interest

\section{REFERENCES}

1. Merskey H.: in The Classification of Chronic Pain Descriptions of Chronic Pain Syndromes and Definitions of Pain Terms, 2th ed., Merskey H., Bogduk N. Eds., p. 207, IASP Press, Seattle 1994.

2. Wolkerstorfer A., Handler N., Buschmann H.: Bioorg. Med. Chem. Lett. 26, 1103 (2016).

3. Maizels M., McCarberg B.: Am. Fam. Physician. 71, 483 (2005).

4. Raffa R.B.: J. Clin. Pharm. Ther. 26, 257 (2001).

5. Aalykke C., Lauritsen K.: Best Pract. Res. Clin. Gastroenterol. 15, 705 (2001).

6. Simon J.P., Evan Prince S.: J. Appl. Toxicol. 37, 71 (2017).

7. Sari S., Karakurt A., Uslu H., Kaynak F.B., Calis U., et al.: Eur. J. Med. Chem. 124, 407 (2016).
8. Dalkara S., Karakurt A.: Curr. Top. Med. Chem. 12, 1033 (2012).

9. Krafte D.S., Bannon A.W.: Curr. Opin. Pharmacol. 8, 50 (2008).

10. Suter M.R., Kirschmann G., Laedermann C.J., Abriel H., Decosterd I.: Anesthesiology 118, 160 (2013).

11. Kamisli S., Karakurt A., Uyumlu A.B., Satilmis B., Alagoz A., et al.: Balk. Med. J. 30, 94 (2013).

12. Hata A.N., Breyer R.M.: Pharmacol. Ther. 103, 147 (2004).

13. Hwang S.H., Wecksler A.T., Wagner K., Hammock B.D.: Curr. Med. Chem. 20, 1783 (2013).

14. Parente L., Perretti M.: Biochem. Pharmacol. 65, 153 (2003).

15. de Gaetano G., Donati M.B., Cerletti C.: Trends Pharmacol. Sci. 24, 245 (2003).

16. Mukherjee D., Nissen S.E., Topol E.J.: JAMA 286, 954 (2001).

17. Herrero J.F., Romero-Sandoval E.A., Gaitan G., Mazario J.: CNS Drug Rev. 9, 227 (2003).

18. Dogan I.S., Ozdemir Z., Sari S., Bozbey I., Karakurt A., et al.: Med. Chem. Res. 27, 2171 (2018).

19. Eidi A., Oryan S., Zaringhalam J., Rad M.: Pharm. Biol. 54, 549 (2016).

20. Yin Z.Y., Li L., Chu S.S., Sun Q., Ma Z.L. et al.: Sci. Rep. 6, 27129 (2016).

21. Ragab H.M., Bekhit A.A., Rostom S.A., Bekhit A.E.: Curr. Top. Med. Chem. 16, 3569 (2016).

22. Lamie P.F., Philoppes J.N., Rarova L.: Arch. Pharm. (Weinheim). 351, e1700311 (2018).

23. Amir M., Javed S.A., Kumar H.: Ind. J. Chem. 46B, 1014 (2007).

24. Schenone S., Brullo C., Bruno O., Bondavalli F., Ranise A., et al.: Bioorg. Med. Chem. Res. 14, 1698 (2006).

25. Tozkoparan B., Kupeli E., Yesilada E., Ertan M.: Bioorg. Med. Chem. Res. 15, 1808 (2007).

26. Amir M., Saifullah K., Akhter W.: J. Enzyme Inhib. Med. Chem. 26, 141 (2011).

27. Sowmya D.V., Basha S.S., Maheswari Devi P.U., Lavanyalatha Y., et al.: Med. Chem. Res. 26, 1010 (2017).

28. Tiperciuc B., Parvu A., Tamaian R., Nastasa C., Ionut I., et al.: Arch. Pharm. Res. 36(6), 702 (2013).

(C) 2020 by Polish Pharmaceutical Society. This is an open-access article under the CC BY NC license (c) () (9) (http://creativecommons.org/licenses/by-nc/4.0/). 